Case Study

\title{
Effects of matrix rhythm therapy on primary lymphedema: a case report
}

\author{
Ayse NerimanNarin, PT ${ }^{1)^{*}}$,AyseZenginAlpozgen,PT ${ }^{2)}$,Hilal DenizogluKulli, MSc, PT 3 ) \\ 1) K.D. School of Physical Therapy and Rehabilitation, Abant Izzet Baysal University: Golkoy, Merkez, \\ Bolu, Turkey \\ 2) Division of Physiotherapy and Rehabilitation, Faculty of Health Sciences, Istanbul University, \\ Turkey \\ 3) Physical Therapy and Rehabilitation Department, Faculty of Health Sciences, Bezmi Alem \\ University, Turkey
}

\begin{abstract}
Purpose] Primary lymphedema occurs because of genetic predisposition and developmental insufficiency of the lymphatic system. Matrix Rhythm Therapy was developed as an external and dynamic method that supplies rhythmic mobilization of the fluids in tissues. The aim of the study was to investigate the effects of Matrix Rhythm Therapy in primary lymphedema. [Subject and Methods] A 36-year-old female with left lower limb lymphedema was evaluated. Leg circumference was measured before and at the end of treatment, and 1 and 3 months later. The circumferences were converted to volumetric values. Twenty sessions of Matrix Rhythm Therapy (5 days/ week) were applied to the affected leg, spine, and abdominal regions. Patient satisfaction was assessed with the Global Rating of Change scale. [Results] Volumetric values were $1,573.28 \mathrm{ml}$ before treatment, 1,573.13 $\mathrm{ml}$ at the end of treatment, $1,516.70 \mathrm{ml} 1$ month later, and 1,441.61 $\mathrm{ml} 3$ months later. At the end of treatment, the volumetric reduction was not significant; however, when compared with baseline, measurements at 1 and 3 months decreased by $3.59 \%$ and $8.36 \%$, respectively. The Global Rating of Change score was 2. [Conclusion] Matrix Rhythm Therapy could not reduce lymphedema when used alone, but long-term treatment may show positive effects.

Key words: Lower limb, Matrix Rhythm Therapy, Primary lymphedema
\end{abstract}

(This article was submitted Mar. 8, 2016, and was accepted May 14, 2016)

\section{INTRODUCTION}

Primary lymphedema is usually idiopathic, without a family history, and defined by the age of onset ${ }^{1,2)}$. It is characterized by swelling of the tissues and thickening and hardening of the skin and soft tissue ${ }^{3,4)}$. The first indication of primary lymphedema is usually swelling of the feet and ankles, and is predominant in women ${ }^{5)}$. The prevalence is difficult to determine and estimates vary considerably6). Up to half of all cases of lymphedema may be primary in origin ${ }^{7}$.

Lymphedema has adverse physical, psychological, and socioeconomic impact, and treatment is continued for life ${ }^{5)}$. The best practice management of lymphedema uses a holistic, multidisciplinary approach that includes exercise/movement, swelling reduction and prevention (compression and/or massage), skin care, risk reduction, and pain and psychosocial management ${ }^{6)}$.

Matrix Rhythm Therapy (MRT) provides vibromassage and aims to induce correct metabolism through a specific physiological pulse. The MRT device activates and rebalances specific vibration in skeletal muscles and the nervous system. The device produces an oscillating rhythm that maximizes lymphatic venous perfusion of the extracellular space in which the anti-edematous effects originate ${ }^{8-10)}$. Studies are needed to investigate the principles and broader applications of MRT. There are few studies describing clinical experiences and the effectiveness of MRT, and there is a low level of evidence for its

*Corresponding author. Ayse Neriman Narin (E-mail: nayseyilmaz@gmail.com)

(C2016 The Society of Physical Therapy Science. Published by IPEC Inc.

This is an open-access article distributed under the terms of the Creative Commons Attribution Non-Commercial No Derivatives (by-nc-nd) License $<$ http://creativecommons.org/licenses/by-nc-nd/4.0/>. 
effectiveness ${ }^{11-13)}$. There is no report in the literature on the effects of MRT in lymphedema. Therefore, the effects of MRT in a case of primary lymphedema.

\section{SUBJECT AND METHODS}

A 36-year-old female (height: $160 \mathrm{~cm}$, weight: $55 \mathrm{~kg}$, body mass index: $21.5 \mathrm{~kg} / \mathrm{m}^{2}$ ) with no history of trauma or surgery had symptoms in the left lower limb for 9 years and was diagnosed with primary lymphedema. She was an office worker and spent the day in a sitting position. She had used knee-high compression hosiery for 4 years, but had not received any treatment for lymphedema or any medication to reduce edema. Her symptoms worsened, and she was seen in the department of rehabilitation. A specialist evaluated her edema and the patient provided written consent for treatment. She had no pain and her joints had full range of motion.

Circumferential measurement is the most widely used method to calculate limb volume ${ }^{14)}$. Measurements are taken at fixed anatomical points along the limb and repeated at different levels ${ }^{15-17}$ ). Circumference was measured before and at the end of treatment, and 1 and 3 months later, to assess lymphedema. The lower limb was measured at 9 levels (metatarsophalangeal joint, ankle, 10, 15, and $20 \mathrm{~cm}$ above the ankle, knee, and 10, 15, and $20 \mathrm{~cm}$ above the knee). Both lower limbs were measured for comparison of circumferences at the same anatomic locations. Circumferential measurements are entered into a formula for calculation of limb volume based on a conical frustrum, to aid in diagnosis and monitor the effect of treatment ${ }^{5}$.

For management of lymphedema, MRT is applied with an electrically powered oscillator (resonator). The mechanical oscillations produce a visually detectable longitudinal motion in the musculature ${ }^{9,10)}$. MRT was applied to the thoracic and lumbar spine, abdominal area, and affected limb in elevation. During treatment, the patient was in a horizontal position. A resonator is used to reactivate cell and tissue metabolism by inducing deep distention at $8-12 \mathrm{~Hz}$. Twenty treatment sessions ( 5 days/week) were performed by a physiotherapist trained and certified in the MRT program. The patient was allowed to continue use of the same compression hosiery during working hours.

The patient was educated about the risks of lymphedema, daily living recommendations, and use of appropriate compression garments. She was also given preventive advice, including proper skin care and was advised to be more active.

The Global Rating of Change (GRC) scales were used to evaluate patient satisfaction and quantify improvement. The GRC scales offer a flexible, quick, and simple method for charting self-assessed clinical progress ${ }^{18}$. The patient would rate her condition compared to the beginning of treatment as improved significantly (2), improved slightly (1), stayed the same $(0)$, deteriorated slightly $(-1)$, or deteriorated significantly $(-2)$.

This case study complied with the ethical standards of the Declaration of Helsinki (1975, revised 1983). The study was approved by the ethics committee of a university. The patient provided written informed consent.

\section{RESULTS}

Circumferential measurements taken at 9 levels before treatment showed more than $2 \mathrm{~cm}$ of fixed lymphedema at the metatarsophalangeal joint, ankle, and 10 and $15 \mathrm{~cm}$ above the ankle. The volumetric value of the left lower limb was $1,573.28 \mathrm{ml}$ before treatment, $1,573.13 \mathrm{ml}$ at the end of treatment, 1,516.70 $\mathrm{ml} 1$ month later, and 1,441.61 ml 3 months later. No reductions in volumetric measurements were observed at the end of treatment. Reduction is determined by subtracting the lymphedema volume of the affected limb at the end of treatment from the volume before treatment. Volume reduction was $0.15 \mathrm{ml}$. Percent reduction is calculated as volume reduction divided by baseline volume multiplied by 100 . When measurements at 1 and 3 months were compared with baseline measurements, there was a decrease in the lymphedema (3.59\% and $8.36 \%$, respectively). The GRC score was 2 at the end of treatment. The patient reported satisfaction with the treatment, reduction in the sense of stiffness and heaviness, and eased mobility in the ankle; the baseline edema was reduced and softened during the treatment process.

\section{DISCUSSION}

We hypothesized that MRT could be an alternative or additional treatment option for patients with primary lymphedema because it has anti-edematous effects. Based on the results in this case, we could not conclude that MRT is effective in reducing lymphedema, but it may show a positive effect by reducing edema in the long term.

The presence and severity of swelling is measured objectively by comparing the circumference or volume of the affected limb to that of the unaffected limb ${ }^{19}$. In the current study, water displacement and optoelectronic measurements, which are other valid methods, were not preferred for the evaluation of lymphedema because of time, cost, difficulty of use, and equipment requirements ${ }^{6,19}$. Instead, circumferential measurement, which is a simple, inexpensive, non-invasive, and easy method, was preferred to evaluate lymphedema.

Similar to massage, which has beneficial effects on circulation, edema, and lymphatic drainage, MRT can cause afferent stimulation through the effect of vibration ${ }^{20)}$. Button et al. reported that vibration therapy increased blood flow ${ }^{21)}$. Although MRT seems appropriate for musculoskeletal injuries, because of implementation by direct skin contact, it could affect the superficial lymphatic system. However, there are only a few studies on the effectiveness of MRT. MRT for burns, sports 
injuries, and circulation has been reported in the literature ${ }^{10-13)}$. No previous study has investigated the effects of MRT on lymphedema. Taspinar et al. investigated the acute effects of MRT on blood circulation in comparison with conventional massage, and reported that MRT was more effective ${ }^{11)}$.

We did not observe reductions in volumetric measurements at the end of treatment. However, a decrease in measurements was observed at 1 and 3 months. This suggested that lymphedema mobilization might start at the proximal extremity. The findings can also be interpreted as the sustained long-term effect of MRT at the cellular level. Although there was only a slight difference in lymphedema volume at the end of treatment, there was a decrease at follow up. Using the percentage difference in limb volume is likely to be most appropriate, because this takes into account the inter-individual differences in limb size. This method is recommended by the Australasian Lymphology Association ${ }^{22}$. This finding indicated that MRT may provide clinical benefits in the long term.

One of the limitations of the present study was the lack of compression therapy. There is agreement among reviews that Complex Decongestive Physiotherapy (CDP) is effective at reducing limb volume ${ }^{23,24)}$. It is an intensive treatment program involving manual lymphatic drainage (MLD), skin care, compression therapy, and/or prescribed exercises ${ }^{23}$. Since these techniques can also be offered separately, it would be useful to determine the effectiveness of each component ${ }^{19)}$. MLD is a specialized form of light massage that is used to assist the flow of lymph from distal areas of stasis to proximal, normally functioning lymphatic vessels ${ }^{19}$ ). The reported effect of MLD on lymphedema is inconsistent. MLD seems to be effective when used with compression therapy, but the available evidence does not support its use as a stand-alone treatment strategy $^{3,23)}$. Compression therapy is an essential part of treatment in lymphedema ${ }^{25}$. Compressive bandages must be left in place 21 to 24 hours per day for optimal volume reduction ${ }^{26)}$. However, in the current study, MRT was applied for only one hour a day and bandaging was not used during the day. The extremity was managed with compression hosiery for only a few hours, less than half of the day, which is inappropriate for lymphedema. Compression hosiery is used mainly for the treatment and prevention of recurrent venous leg ulcers and applies relatively low levels of static compression to the lower leg (up to a maximum of $46 \mathrm{mmHg}$ at the ankle). However, when used as part of lymphedema management, higher levels of compression may be required, involving the use of hosiery capable of achieving at least $49 \mathrm{mmHg}$ at the ankle ${ }^{27)}$. Despite the use of compression hosiery for years, the swelling continued to increase before the patient contacted us, so its continued use would not provide compression sufficient to achieve a volumetric difference. In order to observe the pure effects of MRT, additional compression therapy was not administered. Greater reductions might be demonstrated when the use of MRT is combined with compression therapy for the entire day. Nevertheless, the volume continued to decrease in the follow-up period. Additionally, due to similar application time, application technique, and the effect on the lymphatic system for MRT and MLD, comparative research should be performed to determine whether MRT could be an alternative to MLD. Unfortunately, this is only a case report and there was no control group for comparison.

In conclusion, based on the results of the present case, MRT was not found to be effective in reducing lymphedema when used alone. However, MRT might positively affect lymphedema, which is a chronic process, if it is applied for a longer term and repeated often. To determine the effects of MRT, it would be useful to conduct further follow-up studies with a larger sample size. Furthermore, investigations of MRT compared with MLD are necessary to determine the actual effect. MRT may be combined with compression therapy to manage lymphedema, and could provide a positive contribution to the CDP approach.

\section{REFERENCES}

1) Greene AK, Schook CC: Primary lymphedema: definition of onset based on developmental age. Plast Reconstr Surg, 2012, 129: 221e-222e. [Medline] [CrossRef]

2) Schook CC, Mulliken JB, Fishman SJ, et al.: Primary lymphedema: clinical features and management in 138 pediatric patients. Plast Reconstr Surg, 2011, 127: 2419-2431. [Medline] [CrossRef]

3) Maclellan RA, Greene AK: Lymphedema. Semin Pediatr Surg, 2014, 23: 191-197. [Medline] [CrossRef]

4) Lee BB, Bergan J, Rockson SG: Lymphedema: A Concise Compendium of Theory and Practice. London: Springer, 2011.

5) Wales NH: Strategy for Lymphoedema in Wales: Designed for Lymphoedema. Cardiff: Welsh Assembly Government, 2009.

6) Framework L: Best Practice for the Management of Lymphoedema. International consensus. London: Medical Education Partnership (MEP), 2006.

7) Campisi C, Michelini S, Boccardo F, Societá Italiana di Linfangiologia: Guidelines of the Societá Italiana di Linfangiologia: excerpted sections. Lymphology, 2004, 37: 182-184. [Medline]

8) Randoll UG, Hennig FF: Matrix-Rhythm-Therapy basics theory and practice. Z Physiother, 2009, 61: 1-6.

9) Randoll UG, Hennig FF: Coherent Rhythms (Timing Frequencies) in Biological Systems as a Basis for the Matrix-Rhythm-Therapy. 2003. http://www.drrandoll-institut.de/wp-content/uploads/Coherent-Rhythms_Biological_Systems_MaRhyThe_Berlin2003.pdf (Accessed Sep. 14, 2015)

10) Randoll UG, Hennig FF: Vibrations and their Indication in Sport Injuries. 2003. http://www.marhythe-systems.de/en/research-and-practical-experience/publications (Accessed Sep. 14, 2015)

11) Taspinar F, Aslan UB, Sabir N, et al.: Implementation of matrix rhythm therapy and conventional massage in young females and comparison of their acute effects on circulation. J Altern Complement Med, 2013, 19: 826-832. [Medline] [CrossRef]

12) Sarı Z, Polat MG, Özgül B, et al.: The application of matrix rhythm therapy as a new clinical modality in burn physiotherapy programmes. Burns, 2014, 40 : 909-914. [Medline] [CrossRef] 
13) Sar Z, Polat MG, Özgül B, et al.: A comparison of three different physiotherapy modalities used in the physiotherapy of burns. J Burn Care Res, 2013, 34: e290-e296. [Medline] [CrossRef]

14) Harris SR, Hugi MR, Olivotto IA, et al. Steering Committee for Clinical Practice Guidelines for the Care and Treatment of Breast Cancer: Clinical practice guidelines for the care and treatment of breast cancer: 11. Lymphedema. CMAJ, 2001, 164: 191-199. [Medline]

15) Labs KH, Tschoepl M, Gamba G, et al.: The reliability of leg circumference assessment: a comparison of spring tape measurements and optoelectronic volumetry. Vasc Med, 2000, 5: 69-74. [Medline] [CrossRef]

16) Casley-Smith JR: Measuring and representing peripheral oedema and its alterations. Lymphology, 1994, 27: 56-70. [Medline]

17) Sander AP, Hajer NM, Hemenway K, et al.: Upper-extremity volume measurements in women with lymphedema: a comparison of measurements obtained via water displacement with geometrically determined volume. Phys Ther, 2002, 82: 1201-1212. [Medline]

18) Kamper SJ, Maher CG, Mackay G: Global rating of change scales: a review of strengths and weaknesses and considerations for design. J Manual Manip Ther, 2009, 17: 163-170. [Medline] [CrossRef]

19) Medical Service Advisory Committee: Review of Current Practices and Future Directions in the Diagnosis, Prevention and Treatment of Lymphoedema in Australia. Canberra, Australia: Commonwealth of Australia, 2006.

20) Goats GC: Massage — the scientific basis of an ancient art: Part 2. Physiological and therapeutic effects. Br J Sports Med, 1994, 28: 153-156. [Medline] [CrossRef]

21) Button C, Anderson N, Bradford C, et al.: The effect of multidirectional mechanical vibration on peripheral circulation of humans. Clin Physiol Funct Imaging, 2007, 27: 211-216. [Medline] [CrossRef]

22) Australasian Lymphology Association: Circumferential Measurement Guideline. 2012. http://www.lymphoedema.org.au/public/7/files/Comms/ALA_Circumferential_Measurement_Guideline.pdf. (Accessed Aug. 21, 2015)

23) Finnane A, Janda M, Hayes SC: Review of the evidence of lymphedema treatment effect. Am J Phys Med Rehabil, 2015, 94: 483-498. [Medline] [CrossRef]

24) Leung EY, Tirlapur SA, Meads C: The management of secondary lower limb lymphoedema in cancer patients: a systematic review. Palliat Med, 2015, 29: 112-119. [Medline] [CrossRef]

25) Ochałek K, Gradalski T: Manual lymph drainage may not be a necessary component in lymphedema treatment. J Pain Symptom Manage, 2010, 39: e1-e2. [Medline] [CrossRef]

26) Cheville AL: Current and future trends in lymphedema management: implications for women's health. Phys Med Rehabil Clin N Am, 2007, 18: 539-553, $\mathrm{x}$. [Medline] [CrossRef]

27) Clark M, Krimmel G: Lymphoedema and the construction and classification of compression hosiery. In: MacGregor L (ed.), Compression hosiery in lymphoedema Template for Practice. London: MEP, 2006, pp 2-4. 